\title{
The appearance of urine as a diagnostic aid
}

\section{Sir}

The appearance of urine is not often a clear diagnostic aid in the management of an unconscious patient. In the following case the appearance of the urine was not only diagnostic, but pathognomonic. Awareness of this clinical sign by the admitting medical staff should allow immediate diagnosis.

A 27-year-old woman was brought to the Accident \& Emergency Department at midday. On arrival she was unconscious, unresponsive to painful stimuli, areflexic, with an equivocal plantar response, slowly reacting dilated pupils and normal fundoscopy. She was clinicaly dehydrated, flushed and febrile, with a temperature of $39 \cdot 2^{\circ} \mathrm{C}$, a sinus tachycardia of 140 beats $/ \mathrm{min}$, and her blood pressure was $100 / 60 \mathrm{mmHg}$. Heart sounds were normal. Her respiratory rate was $40 / \mathrm{min}$. There was old food present in the oropharnys. Examination of the chest confirmed inspiratory rhonchi and coarse creps in the right base. Abdominal examination confirmed a tense full bladder. There was a fine metallic silver flecked appearance on the skin of the upper inner thighs and the genital area. There was no evidence of a skin rash.

Catheterization drained $2000 \mathrm{ml}$ of blood-stained urine containing a dense array of shimmering crystals. Urinanalysis showed blood $^{\times \times x}$, protein $^{\times \times}, \mathrm{pH}^{\times} \cdot 0$, specific gravity of 1.015 and debris ${ }^{\times \times \times}$.

We later discovered that she was epileptic, controlled on primidone $250 \mathrm{mg}$ and clonazepam $2 \mathrm{mg}$ taken 8-hourly. She had just recently separated from her boyfriend. Serum barbiturate level, measured on admission, was $75.0 \mathrm{mg} / 1$ (therapeutic range 15$40 \mathrm{mg} / \mathrm{l})$. Transfer to the intensive care unit for ventilation and intensive supportive care resulted in full recovery 2 days later.

This case highlights the diagnostic significance of massive crystalluria in an unconscious patient. Initially described by Morley \& Wynne (1957), it is indicative of severe primidone poisoning. A constant fraction of primidone is metabolized to phenobarbitone in the liver by a rate limited enzymic step. This results in excess accumulation of primidone in an 'overdose' situation. The drug has little protein binding, facilitating glomerular filtration. The hexagonal crystals precipitated in the urine represent unchanged primidone. There is a close correlation between serum drug concentrations and crystalluria (Lehmann, 1987). In the eight clinical cases reported to date, there is little evidence to suggest long-term renal damage.

The use of barbiturates in clinical practice is now uncommon. In turn, this has reduced the incidence of barbituate overdose. This case highlights an important diagnostic finding in the unconscious patient when no history is available. Prompt diagnosis allows early and appropiate management. An unconscius patient with crystalluria should be treated as having taken a primidone overdose. Serum barbituate levels will confirm the diagnosis.

\section{N. MURPHY}

Accident and Emergency Department, Milton Keynes General Hospital, Milton Keynes, England 


\section{REFERENCES}

Lehmann D. F. (1987) Primidone crystalluria following overdose-a report of a case and an analysis of the $\frac{3}{3}$ literature. Medical Toxicology 2, 383-7.

Morley D. \& Wynne N. A. (1957) Acute primidone poisoning in a child. British Medical fournal 1, 90.

\section{Serum potassium response to nebulized salbutamol}

Sir

If the adrenalin-mediated side-effects of nebulized Salbutamol were entirely determined by its systemic absorption, one would have expected to have demonstrated a $\vec{\circ}$ significant correlation between pre-treatment, peak expiratory flow rate (PEFR) and $\vec{\omega}$ hypokalaemia. In our study, however, patients 5,17 and 19 failed to respond in a $\frac{\odot}{\Phi}$ manner that was in keeping with this postulation. Similarly, the quoted discrepancies $\underline{3}$. noted by Ind et al. and Zimmerman indicate that there is more to the problem than mere absorption, important as this factor might be.

My own feelings are that in a given patient, the hypokalaemic response to Salbutamol $\stackrel{\infty}{v}$

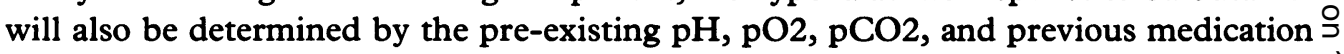
(corticosteroids, Theophylline, etc). Interestingly, our study indicates that if an attack $\vec{\nabla}$ of asthma is severe enough to induce respiratory acidosis, nebulized Salbutamol does not induce hypokalaemia.

There is now a trend towards administering intravenous potassium supplements $\stackrel{\mathbb{Q}}{\circ}$ concurrently with intravenous Salbutamol. With regards to nebulized Salbutamod, $\overrightarrow{0}$ however, there are two paths to consider. Once can either begin to use potassiu更 $\infty$ supplements routinely, or one can try and identify specific patient subgroups who are risk of developing hypokalaemia. Hopefully, we shall soon be treated to a good qualit study, based on the latter more logical approach.

\section{J. DACRUZ}

Department of Accident and Emergency,

Torbay Hospital,

Torquay,

South Devon, England

\section{Trauma audit}

Sir

May I comment on some of the logical and statistical aspects of the interesting series of papers on trauma audit in the June issue of Archives of Emergency Medicine.

The concept of Probability of survival or of death is crucial to these studies. In the numerical form of say Ps $=0.6$ derived from TRISS or from ISS/Age, the implication is ${ }^{\circ}$ that of 10 such cases it is estimated that 6 will survive and 4 will die. The particular patient may be one of the ' 4 ' or one of the ' 6 '. It follows that the use of the Ps value in respect of a single case is quite limited. It might conceivably be used like the 'form' of horses as the basis for laying bets but it does not mean that this case is 'expected' to live; nor, if the Ps value were 0.4 , would it mean that he is 'expected' to die. Not all races are ? won by odds-on favourites! 